\title{
MITOS DAN KONTRAMITOS DALAM NOVEL MANTRA PENJINAK ULAR KARYA KUNTOWIJOYO
}

\author{
Ria Kasanova $^{1}$ \& Sri Widjajanti ${ }^{2}$ \\ Prodi Bahasa Indonesia ${ }^{1}$, Universitas Madura ${ }^{2}$ \\ kasanovaria@gmail.com
}

\begin{abstract}
ABSTRAK
Mitos sebagai bagian dari kehidupan merupakan salah satu inspirasi lahirnya suatu cipta sastra. Seringkali mitos dijadikan bahan untuk menulis sastra oleh pengarang. Namun, asumsi korelasi antara realitas dan sastra, hadirnya mitos dalam cipta sastra telah melalui sebuah proses kreatif. Fenomena mitos melalui sebuah pemahaman dan interpretasi yang baru. Hal tersebut pada tahap akhir sampai pada wujud kontramitos. Oleh karena itu, wajib dipahami bahwa fenomena mitos itu sendiri seringkali dihadapkan dengan kontramitos pada perjalanan sejarah di dalam masyarakat. Salah satu karya sastra yang kental dengan fenomena mitos adalah Novel Mantra Penjinak Ular karya Kuntowijoyo. Penelitian ini menggunakan metode deskripsi analisis. Teks data yang akan digunakan bersumber dari data teks Novel Mantra Penjinak Ular karya Kuntowijoyo, kemudian dianalisis dan dideskripsikan sesuai konteks yang dituju yaitu mitos dan kontramitos dalam Novel Mantra Penjinak Ular karya Kuntowijoyo. Mitos dalam novel Mantra Penjinak Ular lebih kental dengan mitos-mitos yang bersifat kosmologis, yaitu mitos yang berhubungan dengan alam. Hal ini tentu saja memengaruhi alam pikiran orang Jawa dalam menentukan arah menghadap sebuah rumah, pemberian nama anak, angka, serta peruntungan sedangkan kontramitos dalam novel Mantra Penjinak Ular Kuntowijoyo mengajak masyarakat untuk meninggalkan mantra-mantra yang berbasis mitos, mistik, dan klenik.
\end{abstract}

Kata kunci: mantra, novel, mitos

\section{A. PENDAHULUAN}

Sastra dan kehidupan merupakan dua bagian yang saling melengkapi sebagai suatu yang tidak terpisahkan dalam bentuk eksistensi. Sebagai sentuk seni, sastra hadir dalam memberikan nilai-nilai dalam kehidupan. Hal tersebut terjadi karena sastra dan pencipta karya sastra merupakan bagian dari kehidupan itu sendiri (Suyitno, 1986: 3).
Dalam proses penciptaan, karya sastra tidak dapat dipisahkan dari proses mimesis. Hubungan sastra dengan kehidupan memiliki hubungan yang tidak sederhana. Interaksi sastra dengan kehidupan merupakan wujud interaksi yang kompleks. Berhadapan dengan karya sastra, pembaca dihadapkan dengan dua keadaan yaitu proses kreatif dan mimesis. Membaca teks sebagai 


\section{DEIKSIS - JURNAL PENDIDIKAN BAHASA DAN SASTRA INDONESIA}

cerminan kehidupan merupakan hal yang menyesatkan, tetapi membaca teks sastra sebagai rekaan saja juga dapat menyesatkan (Teeuw, 1988: 231).

Kehadiran sastra selalu berada pada dua kutub, yaitu konvensi dan inovasi. Hal ini menunjukkan bahwa dalam sebuah proses kreasi sastra, kenyataan yang muncul dihadirkan pada bentuk yang kompleks dan bervariasi. Proses penciptaan karya sastra menjadi bagian yang penting dalam sebuah teks sastra telah melewati proses kreatif yang terdapat pada diri sang pengarang. Sederhananya dapat dijelaskan bahwa realitas sosial sebuah kemasyarakat hanya sebatas bahan mentah yang perlu membutuhkan pengolahan kembali. Karya sastra begitu saja lahir dari sebuah fenomena lugas, namun demikian sastra hadir dari kesadaran pengarannya bahwa sastra sebagai sesuatu yang imajinasi, inventif, dan fiksi (Suyitno, 1986: 3).

Salah satu yang menarik dari kehidupan manusia adalah adanya fenomena mitos. Mitos merupakan produk perjalanan budaya yang dihadrikan dalam bentuk yang unik. Mitos merupakan suatu bentuk komunikasi yang menghadirkan pesan bersangkutan dengan aturan masa lalu, ide, ingatan serta kenangan (Barthes, 1981: 193). Oleh karena itu, fenomena mitos bukan merupakan suatu wujud benda, atau gagasan, tetapi suatu lambang diskursus atau wacana. Mitos dilambangkan dengan benda (Hasanudin, 1998: 2). Dalam pandangan semiotik, fenomena mitos adalah sebagai sistem semiotik, yaitu hadirnya tanda, penanda, serta yang ditandai.
Mitos sebagai bagian dari kehidupan merupakan salah satu inspirasi lahirnya suatu cipta sastra. Seringkali mitos dijadikan bahan untuk menulis sastra oleh pengarang. Namun, asumsi korelasi antara realitas dan sastra, hadirnya mitos dalam cipta sastra telah melalui sebuah proses kreatif. Fenomena mitos melalui sebuah pemahaman dan interpretasi yang baru. Hal tersebut pada tahap akhir sampai pada wujud kontramitos. Oleh karena itu, wajib dipahami bahwa fenomena mitos itu sendiri seringkali dihadapkan dengan kontramitos pada perjalanan sejarah di dalam masyarakat.

Novel Mantra Penjinak Ular adalah salah satu karya sastra dalam bentuk prosa yang ditulis oleh Kuntowijoyo yang kental dengan dua hal, yaitu nilai budaya dan Islam. Nilai budaya yang muncul dalam novel ini lebih banyak bercerita tentang fenomena sosial yang dibalut dengan budaya Jawa serta dibumbui dengan hal-hal yang berbau mitos seputar sosial, politik, dan budaya.

Novel Mantra Penjinak Ular adalah salah satu karya sastra yang berpijak pada kebudayaan Jawa-Islam, dengan konsep wayang yang diceritakan dengan lugas, dan bertaburan simbol-simbol yang bagi masyarakat Jawa mudah dipahami. Novel ini merupakan catatan etnografis sekaligus catatan sejaran khususnya bagi masyarakat kaki Gunung Lawu sampai dengan persoalan besar tentang politik dan jaring kekuasaan pada masa Orde Baru sampai pada keruntuhannya. Hal inilah yang membuat penulis tertarik untuk menelaah lebih dalam mengenai mitos sekaligus kontramitos dalam 


\section{DEIKSIS - JURNAL PENDIDIKAN BAHASA DAN SASTRA INDONESIA}

Novel Mantra Penjinak Ular karya Kuntowijoyo.

\section{B. METODE PENELITIAN}

Metode penelitian yang digunakan untuk menganalisis novel Mantra Penjinak Ular ini menggunakan metode deskripsi analisis. Penelitian ini memiliki tujuan untuk mendeskripsikan mitos serta kontramitos yang terkandung dalam teks Novel Mantra Penjinak Ular karya Kuntowijoyo, yang kemudian dianalisis dan diambil simpulan. Data pembahasan bersumber pada teks data Novel Mantra Penjinak Ular karya Kuntowijoyo yang telah dan dikumpulkan kemudian dipilah menjadi data yang masuk pada mitos dan kontramitos. Teks data yang akan digunakan bersumber dari data teks Novel Mantra Penjinak Ular karya Kuntowijoyo, kemudian dianalisis dan dideskripsikan sesuai konteks yang dituju yaitu fenomena mitos dan kontramitos.

\section{PEMBAHASAN HASIL PENELITIAN}

Masalah pokok yang terdapat dalam novel Mantra Penjinak Ular adalah masalah politik dan kesenian. Perubahan masyarakat agraris yang berpijak pada mitos menuju masyarakat modern yang lebih berpikir logis. Oleh karena itu, terjadi perubahan sosial budaya dengan dinamika politik yang modern pada masa orde baru. Dengan demikian, novel Mantra Penjinak Ular dapat dikatakan sebagai catatan etnografi perubahan sosial budaya masyarakat Jawa pada masa pemerintahan orde baru. Perubahan masyarakat tradisional dengan pemikiran yang masih lekat dengan hal-hal yang berbau mitos seringkali dijadikan sandaran untuk berperilaku. Dalam novel ini, Kuntowijoyo mengungkap mitos-mitos yang muncul serta kontramitos sebagai pesan akhir agar masyarakat mulai berpikir rasional.

\section{Mitos dalam novel Mantra Penjinak Ular Karya Kuntowijoyo}

Mitos dalam novel mantra penjinak sendiri lebih kental dengan mitos-mitos yang bersifat kosmologis, yaitu mitos yang berhubungan dengan alam. Hal ini tentu saja memengaruhi alam pikiran orang Jawa dalam menentukan arah menghadap sebuah rumah, pemberian nama anak, angka, serta peruntungan. Malinowski (1979: 101) mengatakan bahwa mitos bukan hanya sekadar cerita yang dikisahkan, lebih dari itu mitos merupakan kenyataan yang dihayati. Mitos merupakan daya yang aktif dalam masyarakat primitif. Atas dasar realitas atau kenyataan, mitos dijadikan penghubung dari sebuah institusi-institusi sosial yang ada di dalam masyarakat (Minsarwati, 2002: 27). Kutipan berikut merupakan salah bentuk pemitosan pemberian nama kepada anak dalam masyarakat Jawa, khususnya dalam novel Mantra Penjinak Ular karya Kuntowijoyo.

Pada hari ke lima, diadakan sepasaran dengan mengundang macapatan dan gamelan sederhana. Dengan bangga kakek itu mengumumkan bahwa cucunya diberi nama Abu Kasan Sapari. Abu diambil dari nama sahabat Nabi Abu Bakar, Kasan adalah nama сиси Nabi, dan Sapar adalah bulan 


\section{DEIKSIS - JURNAL PENDIDIKAN BAHASA DAN SASTRA INDONESIA}

perkawinan kedua orangtuanya. Diharapkan bahwa nama tersebut ada pengaruhnya kepada jabang bayi yang baru lahir. Kemudian dengan suara serak seseorang tua melagukan Dandanggula, peninggalan Sunan Kalijaga yang berisi doa keselamatan (Kuntowijoyo, 2010:2)

Pada teks di atas terdapat mitos yaitu dihadirkan yaitu berkenaan pemberian nama anak yang dikaitkan dengan nama orang-orang yang dimuliakan, seperti halnya kelahiran Abu Kasan Sapari, yang berasal dari nama Abu yang berasal dari nama Sahabat nabi Muhammad, kemudian Kasan yang berasal dari nama Hasan yang merupakan cucu nabi Muhammad, dan kemudian Sapari merupakan bulan jadi si anak tersebut. Mitos mengenai pemberian nama anak dengan mengambil nama-nama orang yang dimuliakan bermaksud agar si anak memiliki atau mewarisi sifat dan kebesaran dari nama-nama orang yang dimaksud. Hal ini merupakan fenomenafenomena mitos yang selalu diulang-ulang dalam kehidupan masyarakat Jawa sehingga tradisi ini seolah-olah menjadi sebuah keharusan dan kelaziman.

Tokoh utama dalam novel ini yaitu Abu Kasan Sapari. Tokoh Abu Kasan Sapari lahir di tengah-tengah masyarakat Jawa yang masih memegang erat budaya Jawa dengan berbai macam mitos yang dianutnya. Nama Abu Kasan sendiri merupakan nama yang didapat berdasarkan pertimbangan mitos dalam tradisi masyarakat Jawa, yang diambil dari nama
Abu yaitu sahabat nabi yang bernama Abu Bakar, Kasan yang berasal dari nama cucu Nabi yaitu Hasan, dan Sapar adalah nama bulan yaitu ketika orang tua Abu Kasan menikah.

Pengulangan kembali mitos pada upacara-upacara ritual memiliki arti menghidupkan kembali dimensi sakral atau kudus dalam waktu permulaan. Oleh karena itu bagi masyarakat Jawa khususnya, mengetahui mitos merupakan sesuatu yang dianggap penting karena mitos tidak selalu mengandung tafsiran mengenai dunia beserta isinya dan contoh bentuk mengenai keberadaannya di dunia, lebih dari itu masyarakat harus mengulangi kembali sesuatu yang telah Tuhan serta alam supranatural lakukan di waktu permulaan.

Pohon beringin tua tumbuh lebat di terminal, tidak seorang pun tahu kapan ditanam dan siapa menanam. Begitu tua pohon itu, sehingga dulu ada orang yang menganggapnya bertuah. Orang yang akan mantu memakai rantingnya sebagai hiasan dengan harapan mempelai akan panjang umur subur makmur, mencari daun lumah-kurep (jatuh menghadap ke atas dan ke bawah) dengan harapan mempelai akan rukun, segera punya anak. Ringin artinya juga mari kepengin (tidak kepengin), sebab orang yang sudah kawin harus berhenti menginginkan pasangan. Tidak diketahui siapa yang memulai,tapi setiap bulan Mulud pasti ada pertunjukan wayang di situ. Kemudian perayaan itu tetap, namun orang sudah lupa dengan beringin bertuah dan menganggapnya perayaan itu 


\section{DEIKSIS - JURNAL PENDIDIKAN BAHASA DAN SASTRA INDONESIA}

sebagai bersih desa biasa. Pada waktu itulah warga desa Tegalpandan yang merantau datang untuk ziarah, bertemu keluarga, dan berkumpul dengan teman-teman lama. (Kuntowijoyo, 2010:39)

Kutipan data di atas merupakan
bentuk simbol-simbol kultural yang
tercermin dalam karya sastra yaitu dalam
novel Mantra Penjinak Ular karya Kuntowijoyo. Novel tersebut merupakan salah satu produk budaya yang menyimpan berbagai cerita mitos kedaerahan khususnya pada masyarakat Jawa. Dalam budaya Jawa sarat dengan mitologisasi, sakralisasi, dan mistifikasi (yaitu memandang segala hal sebagai misteri). Semua itu merupakan bentuk mitologi yang dapat didapatkan pada orang, waktu, tempat, dan peristiwa. Hal ini terlihat menonjol dalam pemberian nama, lahiran, waktu, angka, keberuntungan, dan huruf. Oleh karena itu, kenyataan mitos dalam masyarakat Jawa diwujudkan manusia dengan bentuk upacara dan ritual.

Abu Kasan Sapari dididik berperilaku seperti priyayi oleh kakekneneknya yang seorang pedagang. Hal ini disebabkan pandangan masyarakat Jawa bahwa priyayi merupakan kelas atas di dalam masyarakat Jawa yang terhormat, memiliki perilaku tindak-tanduk yang sopan dan dijadikan teladan bagi masyarakat bawah. Dalam pandangan masyarakat Jawa, seorang priyayi merupakan golongan terhormat, golongan yang tidak pantas melakukan kebiasaan-kebiasaan orang-orang bawah atau masyarakat pada umumnya. Aktivitas sehari-hari diisi dengan kegiatan yang bermanfaat seperti belajar, sekolah, dan belajar kesenian tradisional seperti mendalang.

Neneknya melarang dia ke sungai, dan memanjat pohon tinggi, "Kau harus jadi priayi, maka jangan bertingkah seperti petani," katanya. Kakeknya berkata suatu kali, "Jadi orang kecil itu susah. Nasibmu seperti bola, di sepak kesana kemari". Rupanya "filsafat bola" juga masih terpakai, mengerti atau tidak, itulah yang dikatakannya pada Abu kecil. (Kuntowijoyo, 2010:5)

"Kami tidak bisa memberimu kekayaan, tapi tuntutlah ilmu. Kata Nabi, tuntutlah ilmu walaupun sampai negeri Cina. Ilmu itu di saku tidak kentara, dibuang tidak bersuara." Karena itu, selain sekolah di SD, Abu masih harus ke sekolah Diniyah, dan mengaji di surau. Dan selepas Isya' waktu terang bulan, anak-anak lain masih bermain-main, kakeknya akan menyuruhnya pulang, meskipun ia sedang main sembunyi-sembunyian di pematang dekat surau. "Calon priayi tidak boleh begadang," katanya. (Kuntowijoyo, 2010:6)

Mitos mengenai tanda lahir juga menjadi salah satu menarik bagi masyarakat Jawa. Orang Jawa secara turun temurun mempercayai bahwa tanda lahir juga berpengaruh terhadap peruntungan seseorang, baik dalam hal fisik, keberuntungan, kecerdasan, bahkan kekuatan dalam berhubungan intim. Seperti halnya Abu Hasan Sapari kecil 


\section{DEIKSIS - JURNAL PENDIDIKAN BAHASA DAN SASTRA INDONESIA}

yang memiliki ukuran "kemaluan" yang besar mewakili tanda bahwa kelak ia akan menjadi penakluk wanita, disukai wanita, sedangkan bahwa tahi lalat di paha memberikan interpretasi bahwa kelak Abu Hasan Sapari akan kuat dan tahan lama di ranjang. Hal tersebut dapat dilihat pada kutipan berikut;

Di siang hari akan dibawanya berkeliling untuk ditunjukkan temantemannya. "Ini, cucuku. Laki-laki betul. Lihatlah, kacuknya (kelamin anak laki-laki)." Kawan-kawan tuanya yang berhenti bekerja dari sawah atau sedang berteduh di bawah pohon datang merubung. "Wah, kacuknya besar. Ini yang membuat perempuan tergila-gila". "Ada tahi lalat di pahanya. Itu tandanya dia akan tahan lama." "Tidak usah menghabiskan duit untuk obat kuat."

"Membuat wanita megap-megap seperti mujair kehabisan udara."

"Maka, para perempuan pun klenger kena senjata Prabu Baladewa yang bernama Alugara, dok-dok-dok. Alu bentuknya bulat panjang sesuai dengan namanya, gara artinya geger; jadi, alugara ialah alu yang bikin geger. Para perempuan mengerangngerang ... minta ... tambah, dok-dok. Ooo."

"Ee, bukan para perempuan, tapi perempuan saja. Cucu saya hanya kenal satu wanita, istrinya." (Kuntowijoyo, 2006:13)

Mitos seputar ular pun paling dominan dalam novel Mantra Penjinak Ular ini, terutama mengenai ritual atau kepercayaan bahwa seseorang dapat mengendalikan ular dengan cara menguasai Mantra Penjinak Ular. Mantra sendiri adalah sebuah rapalan doa yang dikhususkan untuk hajat tertentu. Namun perbedaan mantra dengan doa, adalah seseorang yang belajar mantra harus melakukan ritual tertentu atau bahkan memiliki pantangan agar mantra yang digunakan dapat manjur;

Tapi Abu tidak peduli, seperti kesetanan ia menyibak kursi-kursi. Menangkap ular dengan tangannya, membawanya berlari keluar halaman kantor dibawah tatapan mata orang banyak. Aman sudah. Orang membuang batu, bata, dan kayu. Orang-orang kembali duduk.

"Halo, halo. Pertunjukan akan dimulai."

Abu Kasan Sapari membawa ular itu ke gerumbul pohonan bambu yang agak jauh dari pelataran kecamatan. Ada tumbuhan liar, batu, dan kebun kosong. Ular itu masih di tangan Abu. Ia menengok ke kanan dan ke kiri. Tidak ada orang. Ia berjongkok.

"Mengapa kau datang menonton, pertunjukan itu untuk bangsa manusia. Tidak untuk bangsa ular," katanya. Ia sendiri heran, ternyata ia telah berbicara dengan ular itu. Abu membuka tangannya, melepas ular itu. Sebentar ular berhenti, Abu mengerti itu artinya ucapan terima kasih, kemudian menghilang di semak-semak. Ia berdiri, baru menyadari sepenuhnya apa yang telah terjadi dan ia tersenyum. Ia telah menguasai ilmu pejinak ular. Hore! (Kuntowijoyo, 2010:11) 


\section{DEIKSIS - JURNAL PENDIDIKAN BAHASA DAN SASTRA INDONESIA}

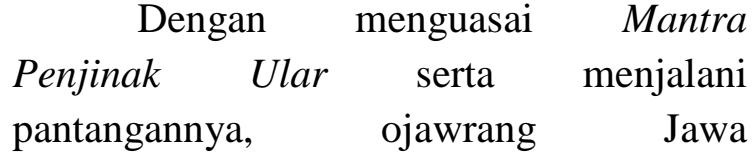
mempercayai bahwa seorang pengguna Mantra Penjinak Ular dapat bersahabat dengan ular, dapat berkomunikasi dengan ular, serta mengendalikan ular tersebut sesuai dengan keinginannya. Seperti halnya tokoh Abu Kasan Sapari yang tidak lagi takut terhadap ular berbisa, bahkan lebih jauh, Abu Kasan Sapari berani memegang serta memindahkan dan berkomunikasi agar ular tersebut tidak lagi mengganggu manusia yang lain, seperti halnya seakanakan ia dapat menguasai ilmu tersebut, ia yakin bahwa kemampuannya tersebut akibat tuah dari mantra yang ia amalkan.

Kemudian, Anderson (2008: 10) menafsirkan mitos sebagai sistem simbolsimbol kultural yang dapat membangkitkan loyalitas yang seragam pada sebuah masyarakat, baik berifat horizontal lintas tempat ataupun secara vertikal lintas antarkelas yang dapat dilihat pada kutipan berikut;

Rumah orang Jawa menghadap ke utara atau selatan, tidak timur atau barat, ternyata ada hubungannya dengan angin. Hanya masjid dan surau menghadap ke timur. Dulu alasannya menghadap utara atau selatan karena meniru atau menghadap keraton. Itu sah-sah saja, tapi yang penting soal angin itu. (Kuntowijoyo, 2010: 29).

Begitu juga dengan kepercayaan terhadap benda-benda yang memiliki kekuatan gaib, orang Jawa masih mempercayai ada beragam benda yang memiliki kekuatan atau kelebihan yang biasanya digunakan untuk berbagai keperluan, misalnya mengusir hujan, sebagai pegangan atau ajimat, bahkan bergerak selayaknya benda hidup. Kepercayaan yang bersifat klenik ini merupakan kepercayaan yang dipercayai secara turun temurun dan dikenal dalam berbagai kelas masyarakat Jawa.

Sama-sama logam ada logam mulia atau tosan aji atau wesi aji. Misalnya keris. Keris yang bukan semata-mata barang hiasan, khasiatnya macam-macam. Ada yang bisa untuk mendiagnosa penyakit, ada yang bisa menyembuhkan, dan ada yang bisa untuk nyumpah. O, ya. Saya pernah melihat sendiri keris yang bisa berdiri diujungnya, kabarnya karena ampuh atau perbuatan jin. (Kuntowijoyo, 2010:35)

Dengan demikian, jelas bahwa mitos bagi orang Jawa bukan sekadar pemikiran intelektual dan bukan juga hasil logika, melainkan lebih pada adaptasi spiritual dan serta mental untuk berkomunikasi dengan yang Illahi.

\section{Kontramitos dalam novel Mantra Pejinak Ular}

Judul dalam novel ini "Mantra Pejinak Ular" memegang peranan yang sangat penting dalam cerita, terlebih pada konteks perubahan sosial dan budaya. Dari masyarakat yang bersandar pada mitos menuju masyarakat yang realistis. Tokoh Abu Kasan Sapari sendiri meskipun seorang 


\section{DEIKSIS - JURNAL PENDIDIKAN BAHASA DAN SASTRA INDONESIA}

priyayi, keturunan Ronggowarsito, tetapi dalam kehidupannya di masyarakat, ia adalah seorang agen sosial, agen perubahan yang bekerja untuk pemerintahan kecamatan. Dengan posisinya di bangkespol ia menjadi motor penggerak yang mengenalkan masyarakat untuk memasuki kehidupan yang modern.

Seluruh usaha kecamatan diarahkan ke desanya. Penataran P-4, perpustakaan desa, kursus baca-tulis (Abu sangsi apakah orang-orang desa masih bisa membaca), papan tulis untuk data desa, dan usahausaha rumah (peternakan kambing, peternakan bebek, dan pembuatan emping mlinjo). Apa boleh buat, semuanya harus serba cepat. Dikerahkannya para mahasiswa Universitas Negeri Sebelas Maret (UNS) yang sedang Kuliah Kerja Nyata (KKN) untuk membantu. (Kuntowijoyo, 2010: 9)

Selain itu, Kuntowijoyo juga mengajarkan kebebasan dalam berekspresi serta kebebasan berpendapat dalam hal politik. Kuntowijoyo menyatakan bahwa kesenian pada dasarnya bukanlah alat politik, kesenian harus kembali pada kodratnya yaitu untuk memanusiakan manusia, bukan memperdayai masyarakat untuk kepentingan tertentu. Kesenian digunakan untuk menyampaikan pesanpesan moral, bukan pesan politik praktis serta kesenian adalah corong untuk menyampaikan keadilan dan demokrasi yang bebas tendensi. Hal ini digambarkan dengan tokoh Abu Kasan
Sapari. Hal ini dijelaskan ketika Abu Kasan Sapari diwawancari oleh seorang jurnalis. Hal ini merupakan sebuah kontramitos bahwa sebelumnya masyarakat meyakini bahwa kesenian yang ada sekarang merupakan corong politik, alat politik praktis yang digunakan untuk menarik publik untuk mendukung seseorang untuk berkuasa.

Sejak saat itulah Abu Kasan Sapari akrab dengan kawan wartawannya. Wartawan itu anggota AJI (Asosiasi Jurnalistik Indonesia). Masih muda, bersemangat. Ia mengatakan pada Abu bahwa jurnalisme dipilihnya sebagai profesi, dan sebagai alat untuk memperjuangkan keadilan dan demokrasi. Ia hanya mengandalkan hati nurani, tidak segan-segan melakukan kritik kepada siapa pun. (Kuntowijoyo, 2010: 35)

Kuntowijoyo juga mengenalkan kepada publik bahwa sebuah pesta demokrasi pada pemerintahan tingkat desa pun tidak lepas dari permainan mesin politik yang menganggap bahwa kemenangan pilkades merupakan tolok ukur kemenangan pemilu, bagi para botoh, kemenangan pilkades merupakan ajang pertaruhan atau perjudian, dan bagi pada dukun, kemenangan pilkades adalah sebuah prestise bagi bisnis perdukunannnya. Proses sebuah pemilihan pilkades tidak sesederhana yang masyarakat pikirkan karena adanya berbagai kekuatan yang bertaruh untuk kemenangan pilkades itu sendiri sehingga siapa pun yang kalah harus siap 


\section{DEIKSIS - JURNAL PENDIDIKAN BAHASA DAN SASTRA INDONESIA}

tersingkir. Termasuk tokoh Abu Kasan Sapari yang dipindah karena dianggap ikut terlibat dalam politik praktis tersebut, meskipun tokoh Abu Kasan Sapari hanya mendalang untuk siapapun yang datang memintanya mendalang. Kuntowijoyo berusaha menggambarkan bahwa fenomena pilkades tidaklah sesederhana yang ada di dalam pemikiran masyarakat karena fenomena politik merupakan fenomena yang rumit dengan proses yang rumit pula.

Randu, botoh, dukun, dan tokohtokoh lokal berusaha mempengaruhi jalannya pemilihan lurah dengan berbagai cara. Kemenangan dalam pemilihan lurah mempunyai makna sendiri bagi yang berkepentingan. Bagi Mesin Politik kemenangan Pilkades berarti kemenangan dalam pemilu nanti, uang bagi botoh, prestise bagi dukun, dan sekadar rezeki bagi orang-orang lain. Di sini akan diceritakan bagaimana mereka bersaing, dan siapa yang memenangkan pertarungan. (Kuntowijoyo, 2010:36).

Di akhir perjalanan tokoh Abu Kasan Sapari untuk memutus mata rantai mengenai mitos mantra penjinak ular. Abu Kasan Sapari bertekad untuk meninggalkan kebiasaan dan kepercayaan masyarakat terhadap kekuatan sebuah mantra yang tidak lagi sesuai dengan realitas yang ada di dalam masyarakat, dan kembali mencoba untuk berpikir logis sesuai perkembangan zaman bahwa sesuatu selayaknya di pandangan dengan masuk akal dan tidak lagi terikat dengan tradisi-tradisi masyarakat yang tidak lagi rasional.

"Begini, Pak. Saya akan melaksanakan anjuran mengenai Ma'ul Hayat itu. Tapi ada halangan." "Halangan? Laki-laki harus berani, rawe-rawe rantas, malang-malang putung."

"Bukan itu, Pak. Lastri minta saya menyingkirkan ular." "Apa susahnya? Bawa saja ular itu ke kebun binatang." "Ular mudah, Pak. Tapi saya terikat dengan mantranya." "Mantra?"

"Ya, Pak. Saya harus mencari orang yang mau ditulari mantra. Mantra harus diturunkan, berkelanjutan sampai kiamat tiba. Kalau tidak saya kena bebendu [malapetaka], tidak akan mati-mati meski tua-renta

"Jangan percaya! Itu gombal, itu sampah. Kau orang beriman. Karenaya malahan kau wajib memutuskan mata rantai sirik itu. Sekarang zaman modern, bukan zamannya mantra lagi." (Kuntowijoyo, 2010:94)

Bagian akhir dalam novel terlihat Abu Kasan Sapari ketika harus meninggalkan ular-ular yang menjadi kesayangannya, dan membuang atau meninggalkan mantra lalu kemudian memasuki kehidupan yang nyata (menikah dengan Lastri, menjadi dalang, dan menjadi pegawai negeri). Peristiwa yang mengisahkan Abu Kasan sapari ketika berpisah dengan ular dan mantranya tersebut, dianggap sebagai sebuah peristiwa yang menyatakan"selamat tinggal mitos dan selamat datang realitas". Dengan demikian 


\section{DEIKSIS - JURNAL PENDIDIKAN BAHASA DAN SASTRA INDONESIA}

Kuntowijoyo ingin menegaskan jika hidup sekarang ini harus berpijak pada sesuatu yang realitas, berorientasi pada ilmu, percaya kepada Illahi, tidak berpijak pada mitos, menjalani klenik, terlebih lagi syirik menyekutukan Tuhan SWT.

Pagi itu dia keluar dari rumahnya dengan sebuah kotak kayu. Lastri mengantar sampai halaman. Abu mengucap terima kasih pada polisi yang mengantarnya sampai terminal. Sebuah bis akan mengantarnya ke bonbin yang terletak di tepi jalan itu. Setiap kali air matanya meleleh, setiap kali pula dipegangnya kotak kayu kuat-kuat dan dibayangkannya Lastri. Ia berketapan menjadi dalang, menjadi penerus tradisi Eyang dan tradisi Ronggowarsito: menghibur dan mengajarkan kebijaksanaan hidup. Langit memerah di atas Gunung Lawu. (Kuntowijoyo, 2010:95)

Keputusan Abu Kasan Sapari untuk mengantarkan ular piaraannya ke kebun binatang dan meninggalkan ikatan mantra penjinak ular merupakan upaya Kuntowijoyo menyadarkan kepada masyarakat untuk mengembalikan sesuatu kepada tempatnya, mengembalikan masyarakat pada realitas kehidupan masyarakat yang telah modern, berpikir logis dan realistis, serta tidak lagi terkungkung dalam mitos-mitos. Namun, meninggalkan pemikiran mitos bukan berarti meninggalkan budaya, Kuntowijoyo dalam novel Mantra penjinak ular-nya mengingatkan bahwa sebagai orang Jawa, haruslah tetap menjaga tradisi leluhur dan terus mengajarkan kebajikan hidup kepada masyarakat.

Dengan novel ini Kuntowijoyo mengajak masyarakat untuk meninggalkan mantra-mantra yang berbasis mitos, mistik, dan klenik. Kemudian, menggantinya dengan ilmu yang berpijak pada realitas dan doa yang langsung mentransendensikan diri kepada Tuhan. Dalam berbagai esai dan artikelnya, berkali-kali Kuntowijoyo menegaskan bahwa ilmu dalam paradigma Islam berpijak pada emansipasi (amar ma'ruf), liberasi (nahyi munkar), dan transendensi (tu'minunabillah).

\section{SIMPULAN}

Mitos dalam novel Mantra Penjinak Ular lebih kental dengan mitos-mitos yang bersifat kosmologis, yaitu mitos yang berhubungan dengan alam. Hal ini tentu saja memengaruhi alam pikiran orang Jawa dalam menentukan arah menghadap sebuah rumah, pemberian nama anak, angka, serta peruntungan, sedangkan kontramitos dalam novel Mantra Penjinak Ular Kuntowijoyo mengajak masyarakat untuk meninggalkan mantra-mantra yang berbasis mitos, mistik, dan klenik.

\section{E. DAFTAR PUSTAKA}

Anderson, Benedict R.O'G. 2008. Mitologi dan Toleransi Orang Jawa. Terj. Revianto B. Santoso dan Luthfi Wulandari. Yogyakarta: Jejak.

Barthes, Roland. 1981. Mithologies. New York: Granada Publising

Barthes, Roland. 1983. S/Z. Terjemahan Bahasa Inggris oleh Richard Miller. Britain:Brasil Blacwell. 


\section{DEIKSIS - JURNAL PENDIDIKAN BAHASA DAN SASTRA INDONESIA}

Hasanuddin. 1998. Pengaruh Mitos dalam Karya Sastra Indonesia Warna Lokal Minangkabau. dalam Majalah Humanus. Lemlit IKIP Padang.

Kuntowijoyo. 2010. Mantra Penjinak Ular. Jakarta: Gramedia

Malinowski, B. 1944. A Scientific Theory of Culture and Other Essays. Chapel Hill: University of North Carolina Press

Minsarwati, Wianu. 2002. Mitos Merapi dan Keasifan Ekologi. Yogyakarta: kreasi wacana

Suyitno. 1986. Sastra Tata Nilai dan Eksegesis. Yogyakarta: Penerbit Hanindita

Teeuw, A.1988. Sastra dan Ilmu sastra. Jakarta: PT Dunia Pustaka Jaya. 